\title{
Synthesis, characterization and drug-delivery activity of rifampin anchored poly(vinyl alcohol)
}

\author{
PALANICHAMY JEYARAMAN, BALAKRISHNAN MEENARATHI \\ and RAMASAMY ANBARASAN* \\ Department of Polymer Technology, Kamaraj College of Engineering and Technology, Virudhunagar 626001 , \\ Tamilnadu, India
}

MS received 26 May 2015; accepted 14 September 2015

\begin{abstract}
Poly(vinyl alcohol) (PVA) has wide applications in film industries owing to the hydrophilicity and biocompatibility. In recent times the application of PVA is extended to drug-delivery field. Unfortunately, the thermal stability of PVA is very poor. In order to increase the thermal stability, the drugs were chemically conjugated with PVA. In the present investigation rifampin (Rif.) a bactericidal antibiotic drug was chemically conjugated with PVA backbone. The resultant Rif.-conjugated PVA was characterized by Fourier transform infrared spectroscopy, UV-visible spectroscopy, nuclear magnetic resonance (NMR) spectroscopy, differential scanning calorimetry, and thermogravimetric analysis (TGA). Finally, the Rif.-conjugated PVA was tested for the drug-release activity. The scanning electron microscope morphology declared the presence of microvoids on the surface of PVA and the same was effectively used for the drug-loading purpose. Mechanical properties of PVA before and after the structural modification process were also tested. The aromatic carbon signal around $120-150 \mathrm{ppm}$ in the ${ }^{13} \mathrm{C}$ NMR confirmed the chemical grafting of Rif. on to the PVA backbone. The TGA confirmed the four-step degradation process for the structurally modified PVA.
\end{abstract}

Keywords. PVA; structural modification; characterization; drug release study.

\section{Introduction}

Poly(vinyl alcohol) (PVA) is a water soluble, film-forming biodegradable synthetic polymer with wide applications [1-5]. In order to improve the bio-medical application of PVA, the structure of PVA should be modified. Owing to the presence of inter- and intra-molecular hydrogen bonding, the availability of free $-\mathrm{OH}$ groups for further interactions are restricted.

PVA offers less number of free hydroxyl groups for drugloading purposes. This problem can be outwitted by the structural modification of PVA. In 2012, Crispim et al [6] modified the structure of PVA by glycidyl methacrylate group towards hydrogel preparation. PVA was structurally modified by Ibuprofen pendant groups [7]. Schmedlen and co-workers [8] reported about the peptide-modified PVA for tissue engineering application. PVA was structurally modified with rifampin (Rif.) and further characterized by WAFS, differential scanning calorimetry (DSC), ultravioletvisible (UV-visible) techniques, and swelling properties [9]. PVA was also structurally modified with isopropylacryl amide [10], hydroxyl acids [11], poly( $\varepsilon$-aprolactone) [12], carboxymethyl chitosan [13], maleic anhydride [14],

\footnotetext{
*Author for correspondence (anbu_may3@yahoo.co.in)
}

poly(lactide-co-glycolide) [15], ethylene diaminetetraacetic acid, and dianhydride [16], guargum [17], sulphosuccinic acid [18], fumaric acid [19] and butaraldehyde [20]. Even after thorough literature survey no report based on the Rif.modified PVA has been reported.

Rif. is a bactericidal antibiotic drug and is used for the treatment for tuberculosis, an airborne communicable [21,22] disease in combination with other drugs [23]. Rif. contains $-\mathrm{OH}$ and $-\mathrm{CONH}-$ functional groups. After the structural modification it can be chemically grafted onto the PVA structure. This is the reason to conjugate Rif. and PVA matrix for an efficient and sustainable release of drug.

\section{Materials and methods}

\subsection{Materials}

PVA (S.D. Fine Chemicals, India, $M_{\mathrm{w}}=125,000 \mathrm{~g} \mathrm{~mol}^{-1}$ ), succinic anhydride (SA, Lobachemie, India), stannous octoate (S.O. Aldrich Chemicals, India), dimethyl sulphoxide (DMSO) ethylene diamine (EDA, Merck, India), N,N'dicyclohexylcarbodiimide (DCC, Spectrochem, India), and rifampin (Rif., Lupin Ltd., India) were purchased and used as such. 


\subsection{Experimental procedures}

2.2a Synthesis of PVA-g-Rif:: The synthesis includes three steps and they are explained below. Required amount of DMSO $(150 \mathrm{ml})$ was taken in a $250 \mathrm{ml}$ beaker. Five grams of PVA was carefully weighed and added pinch by pinch into the DMSO with vigorous stirring, which was mounted on a magnetic stirrer at a temperature of about $85^{\circ} \mathrm{C}$. After the complete dissolution of PVA in DMSO, $2.5 \mathrm{~g}$ of SA was taken and dissolved in the medium. With this $0.001 \mathrm{~g}$ of S.O. (ring opening catalyst) was added. The structural modification reaction was carried out for $2 \mathrm{~h}$. At the end of the reaction acid functionalized PVA was obtained.

Two grams of Rif. drug was accurately weighed and dissolved in $100 \mathrm{ml}$ DMSO taken in a $250 \mathrm{ml}$ beaker. After the complete dissolution of the drug, equal amounts of SA and $0.001 \mathrm{~g} \mathrm{S.O.} \mathrm{were} \mathrm{added} \mathrm{to} \mathrm{the} \mathrm{reaction} \mathrm{medium.} \mathrm{The} \mathrm{stirring}$ was continued for $2 \mathrm{~h}$. The resultant product was the acid functionalized Rif. drug.

The acid functionalized Rif. and PVA were mixed together in a $500 \mathrm{ml}$ beaker in the presence of $5 \mathrm{~g}$ of EDA and DCC under vigorous stirring condition at $85^{\circ} \mathrm{C}$ for $2 \mathrm{~h}$. After the addition of EDA and DCC, the stirring process was continued for $24 \mathrm{~h}$ and the solution was kept for settling process [24,25]. After $60 \mathrm{~min}$ of settling, the solution was filtered and poured onto the Petri dish without any air bubble. The Petri dish was air dried for 7 days at room temperature. The sample was obtained in a film form. The airdried sample was weighed and packed in a zip lock cover (scheme 1).

\subsection{Structural characterization and morphological observations}

Fourier transform infrared (FTIR) spectra for the samples were recorded with the help of Shimadzu $8400 \mathrm{~S}$, Japan Instrument by the $\mathrm{KBr}$ pelletization method from 400 to $4000 \mathrm{~cm}^{-1}$. Briefly, $3 \mathrm{mg}$ of polymer sample was ground with $200 \mathrm{mg}$ spectral grade $\mathrm{KBr}$ and made into disc under the pressure of $7 \mathrm{t} .{ }^{1} \mathrm{H}$ and ${ }^{13} \mathrm{C}$ nuclear magnetic resonance (NMR $500 \mathrm{MHz}$ ) spectra were obtained using Varian, unity Inova $500 \mathrm{NMR}$ in deuterated DMSO solvent. Ultravioletvisible (UV-vis) spectroscopy was recorded with the help of Shimadzu UV 3600 NIR, Japan Instrument. DSC was measured by using Universal V4.4A TA Instruments (simultaneous DSC and TGA analyzer) under nitrogen atmosphere at the heating rate of $10 \mathrm{~K} \mathrm{~min}^{-1}$ from room temperature to $373 \mathrm{~K}$. The thermogravimetric analysis (TGA) curves for the polymer samples were recorded using TA instruments TGA Q50 by heating the materials at the rate of $10 \mathrm{~K} \mathrm{~min}^{-1}$ in an inert (nitrogen) atmosphere. The scanning electron microscope (SEM) images of the samples were taken in a Hitachi S34, Japan Instrument. Mechanical properties were measured by using universal tensile tester, India Instrument.

The drug release study for the Rif.-anchored PVA was carried out and the procedure in brief is presented as follows: Rif.-anchored PVA (0.50 g) was taken in a disc form prepared under the pressure of $7 \mathrm{t}$. In total $500 \mathrm{ml}$ of gastric $\mathrm{pH}$ solution was prepared and the tablet was suspended in the medium with vigorous stirring. Now the drug is slowly released by the hydrolysis mechanism and the same can
PVA $-5 \mathrm{~g}$ in $150 \mathrm{ml}$ of DMSO

$+$

Succinic anhydride $-2.5 \mathrm{~g}$

Stannous octoate- $0.01 \mathrm{~g}$

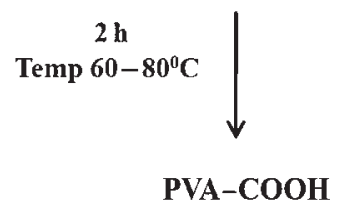

Rifampin $-2 \mathrm{~g}$ in $100 \mathrm{ml}$ of DMSO

Succinic anhydride $-2.5 \mathrm{~g}$
Stannous octoate- $0.01 \mathrm{~g}$

2 h

Temp $60-80^{\circ} \mathrm{C}$

Rifampin-COOH

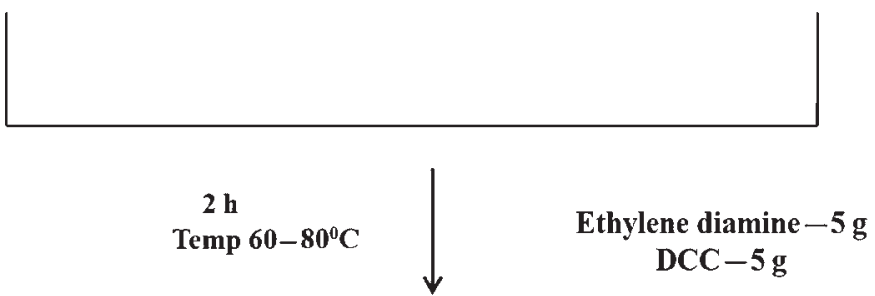

PVA-g-EDA-Rifampin

Scheme 1. Flow chart for the preparation of Rif.-grafted PVA. 
be quantitatively measured at different intervals of time by pipetting $2 \mathrm{ml}$ of aliquot by using UV-visible spectrophotometer. From the calibration curve, the $\%$ cumulative drug release (\% CDR) was calculated as follows:

(Weight of standard $) \times($ sample absorbance $)$

$\% \mathrm{CDR}=\frac{\times(\text { sample dilution }) \times(\text { potency of standard })}{(\text { Standard dilution }) \times(\text { standard absorbance })}$

The drug release mechanism can be determined by using the following plots. For zero-order model, the plot is (\% CDR) vs. time, for first-order model, the plot is $\log (\%$ drug remaining) vs. time, for the Higuchi model, the plot is (\% CDR) $v s$. (time $)^{1 / 2}$, for the Hixson-Cowell model, the plot is $(\%$ drug remaining $)^{1 / 3} v s$. time and for the Koresemeyer-Peppas model, the plot is $\log (\%$ CDR $)$ vs. $\log$ (time) were drawn and their slope, intercept values were noted.

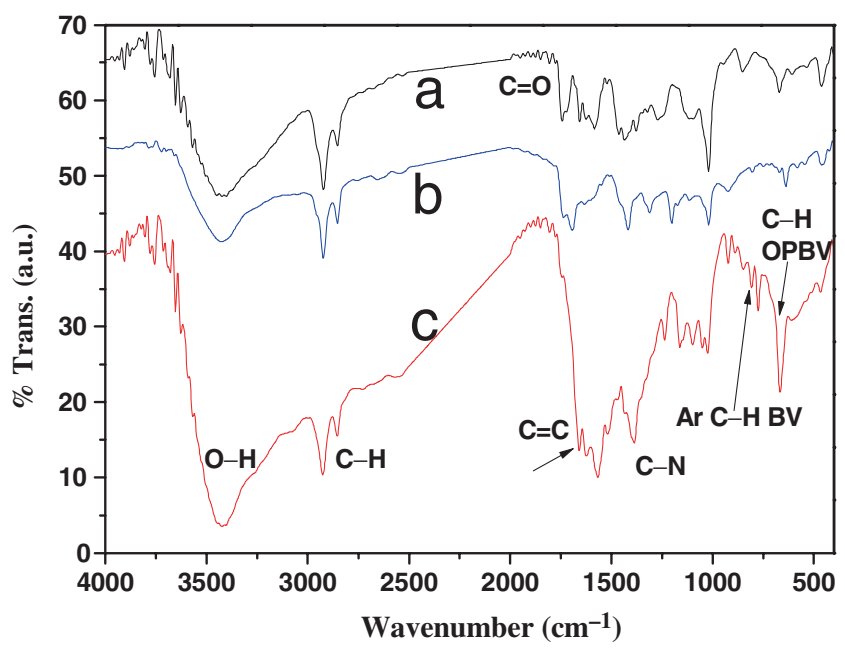

Figure 1. FTIR spectrum of (a) PVA, (b) PVA-SA and (c) PVASA-Rif.

\section{Results and discussion}

\subsection{FTIR study}

The main aim of the present investigation is structural modification of PVA by using Rif. in order to obtain sustainable drug release behaviour. Figure 1a indicates the FTIR spectrum of PVA. The important peaks are characterized as follows: a broad peak around $3400 \mathrm{~cm}^{-1}$ is due to the $-\mathrm{OH}$ stretching of PVA. The $\mathrm{C}-\mathrm{H}$ symmetric and antisymmetric stretching of PVA is observed at 2852 and $2927 \mathrm{~cm}^{-1}$, respectively. A peak at $1741 \mathrm{~cm}^{-1}$ is ascribed to the carbonyl stretching of acetate moieties present in the PVA. PVA here used is $85 \%$ hydrolysed. The $\mathrm{C}-\mathrm{O}-\mathrm{C}$ ester linkage from the acetate moieties can be seen at $1024 \mathrm{~cm}^{-1}$. The $\mathrm{C}-\mathrm{H}$ out of plane bending vibration is noted at $674 \mathrm{~cm}^{-1}$. Figure $1 \mathrm{~b}$ represents the SA-modified PVA. Here also the above said peaks are observed. A doublet peak at 1738 and $1687 \mathrm{~cm}^{-1}$ is responsible for the carbonyl stretching of acetate moieties and SA groups. Figure 1c explains the FTIR spectrum of Rif.-modified PVA. As usual, the $-\mathrm{OH}, \mathrm{C}-\mathrm{H}, \mathrm{C}-\mathrm{H}$ out of plane bending vibration are observed. Apart from these, some new peaks are also observed. A new peak at $1656 \mathrm{~cm}^{-1}$ is due to the $\mathrm{C}=\mathrm{C}$ stretching. The $\mathrm{C}=\mathrm{C}$ is formed during the dissolution of PVA in solvent medium at $85^{\circ} \mathrm{C}$. This olefin bond formation is due to the oxidative degradation reaction. This is in accordance with our earlier publication [26,27]. A sharp peak at $1384 \mathrm{~cm}^{-1}$ is accounted by the $\mathrm{C}-\mathrm{N}$ stretching. The appearance of aromatic $\mathrm{C}-\mathrm{H}$ bending vibration around 810 and $770 \mathrm{~cm}^{-1}$ explains the grafting of Rif. on the PVA backbone. Thus the appearance of new peaks explained the chemical grafting of Rif. on to the SA-modified PVA.

\subsection{NMR study}

The structure of PVA after the chemical grafting with Rif. was confirmed by the NMR spectroscopy. Figure 2A indicates the ${ }^{1} \mathrm{H}$ NMR spectrum of Rif.-grafted PVA peaks at 2.2 and

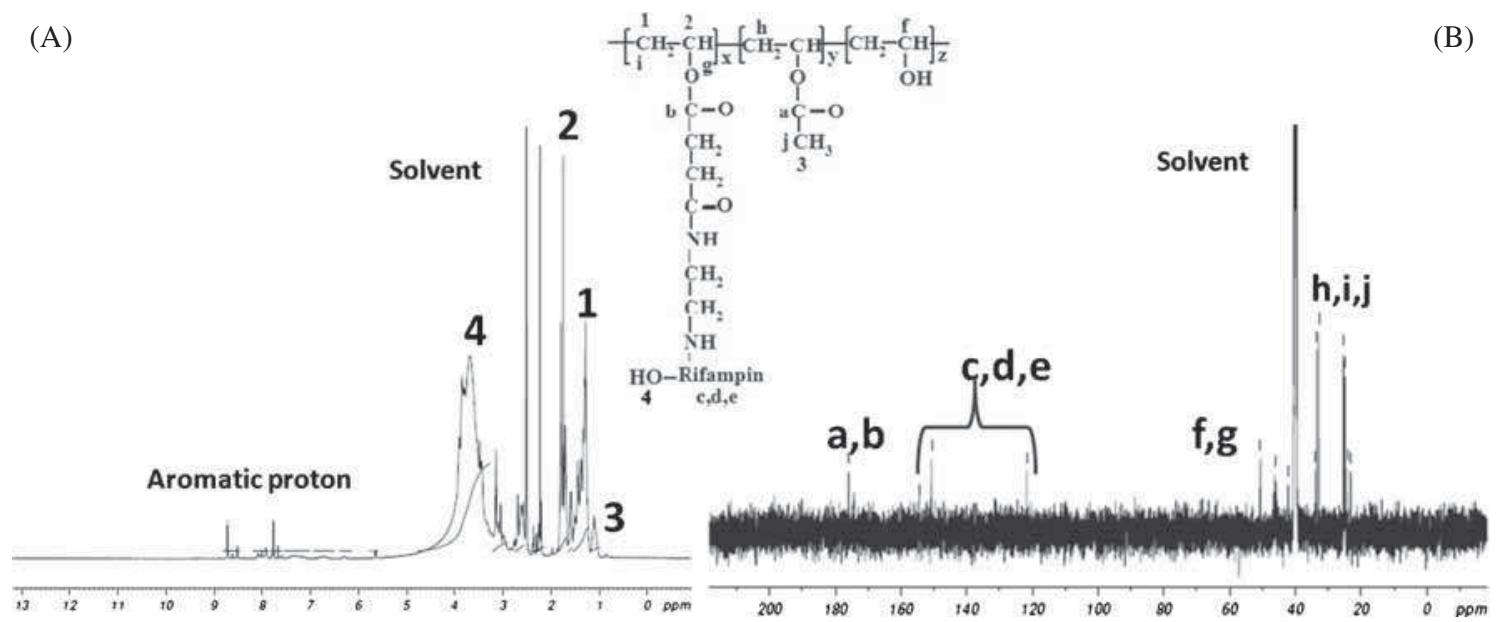

Figure 2. (A) ${ }^{1} \mathrm{H}$ NMR and (B) ${ }^{13} \mathrm{C}$ NMR spectra of PVA- $g$-Rif. 
$2.4 \mathrm{ppm}$ corresponded to the DMSO solvents. The aromatic protons of Rif. appeared between 7.5 and $8.7 \mathrm{ppm}$. The $-\mathrm{OH}$ proton of Rif. appeared at $3.7 \mathrm{ppm}$. The methyl protons of vinyl acetate moieties appeared at $1.1 \mathrm{ppm}$. A multiplet peak at $1.4 \mathrm{ppm}$ and $1.8 \mathrm{ppm}$ are corresponding to methylene proton of vinyl group and $-\mathrm{CH}$ protons of vinyl group, respectively. Further, the structure of Rif.-modified PVA was confirmed by recording ${ }^{13} \mathrm{C}$ NMR spectrum (figure 2B). Peaks at 174 and $175 \mathrm{ppm}$ corresponded to the carbonyl carbon of acetyl group and the carbonyl group was formed at the PVA main chain. The aromatic carbon signals of Rif. appeared at 121, 150 and $154 \mathrm{ppm}$. The methyl carbon signal appeared at $24.8 \mathrm{ppm}$ (from acetate moieties). The acryl carbon signal of PVA is appeared at $33.8 \mathrm{ppm}$ [28]. A broad peak at $39.9 \mathrm{ppm}$ was due to the DMSO solvent. The $\mathrm{C}-\mathrm{H}$ carbon signal of vinyl acetate appeared at $42.1 \mathrm{ppm}$. The $\mathrm{C}-\mathrm{H}$ carbon signal of Rif.-modified PVA appeared at $50.6 \mathrm{ppm}$. The appearance of aromatic carbon confirmed the chemical grafting of Rif. on to SA-modified PVA.

\subsection{UV-visible study}

The UV-visible spectrum of Rif. is shown in figure $3 \mathrm{a}$. The electronic spectrum exhibited two peaks at 338 and $472.48 \mathrm{~nm}$. The first one is due to the $n \rightarrow \pi^{*}$ transition whereas the latter one corresponds to $\pi \rightarrow \pi^{*}$ transition of Rif. The UV-visible spectrum of Rif.-modified PVA is given in figure $3 \mathrm{~b}$. The electronic spectrum showed a broad peak at $436.1 \mathrm{~nm}$ due to the $\pi \rightarrow \pi^{*}$ transition of Rif. The blue shift in the electronic spectrum can be explained as follows: (i) after the chemical grafting reaction, the size of the resultant product may be reduced and (ii) there may be a decrease in electronic conjugation of Rif. The simple chemical modification cannot reduce the size of the PVA or product. Hence, the first possible explanation is ruled out. The second one might be a possible reason because Rif. contains more number of phenyl ring and resonance stabilization may be

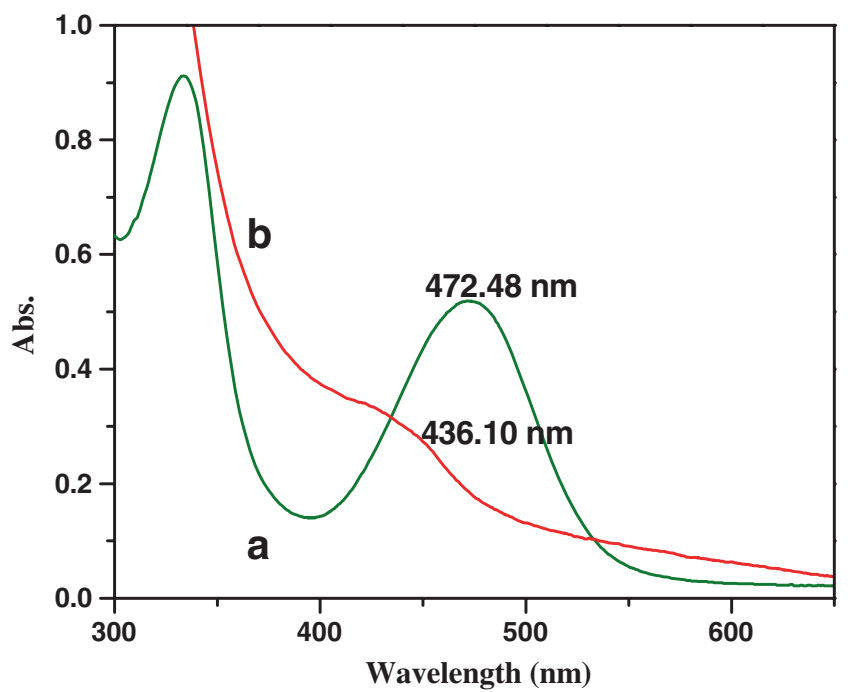

Figure 3. UV-visible spectrum of (a) rifampin and (b) PVA-g-Rif. arrested by the chemical grafting reaction. Moreover, the appearance of $\pi \rightarrow \pi^{*}$ transition after the structural modification confirmed the chemical grafting Rif. on to SAmodified PVA.

\subsection{DSC analysis}

The phase transition of PVA before and after structural modification is given in figure 4. The thermogram (figure 4a) exhibited the first endothermic transition at $85.2^{\circ} \mathrm{C}$ and the same was associated with the $T_{\mathrm{g}}$ of PVA. The $T_{\alpha}$ of PVA is noted at $192^{\circ} \mathrm{C}$. The appearance of $T_{\alpha}$ is an indication of semi-crystalline nature of PVA. The third endothermic transition at $327^{\circ} \mathrm{C}$ was responsible for the melting of PVA crystallites and followed by the degradation reaction. Anbarasan et al [28] explained the change in the phase transitions after the structural modification of PVA. Figure $4 \mathrm{~b}$ demonstrates the DSC thermogram of SA-modified PVA. Here also one can see the $T_{\mathrm{g}}\left(85.9^{\circ} \mathrm{C}\right), T_{\alpha}\left(180.3^{\circ} \mathrm{C}\right)$ due to the SAmodified PVA and $T_{\mathrm{m}}\left(346.9^{\circ} \mathrm{C}\right)$. The DSC results indicate that during the structural modification of PVA, some of the vinyl alcohol units were not modified. This is due to the inter- as well as intra-molecular hydrogen bonding of PVA. This is in accordance with our earlier communication [27]. Figure $4 \mathrm{c}$ demonstrates the DSC thermogram of Rif.-grafted SA-modified PVA. Again one can see a $T_{\mathrm{g}}\left(93.5^{\circ} \mathrm{C}\right)$, $T_{\alpha}\left(185.8^{\circ} \mathrm{C}\right.$ and $\left.206.5^{\circ} \mathrm{C}\right)$, and the $T_{\mathrm{m}}$ value at $316^{\circ} \mathrm{C}$. The appearance of two $T_{\alpha}$ is already explained. On thorough analysis one can come to a conclusion that after the Rif. grafting, the $T_{\mathrm{g}}$ of PVA was increased. It means the crystalline nature of PVA was improved by the way of grafting with Rif. The decrease in $T_{\mathrm{m}}$ is explained on the basis of decrease in molecular weight of PVA due to the oxidative degradation reaction and thermolytic oxidation reaction. During the structural modification the PVA chains undergo to the various chemical reactions such as $\mathrm{C}=\mathrm{C}$ formation, $\mathrm{C}=\mathrm{O}$ formation and $\mathrm{C}-\mathrm{C}$ bond breaking reaction. As a result of $\mathrm{C}-\mathrm{C}$ bond breaking reaction the molecular weight of PVA was reduced.

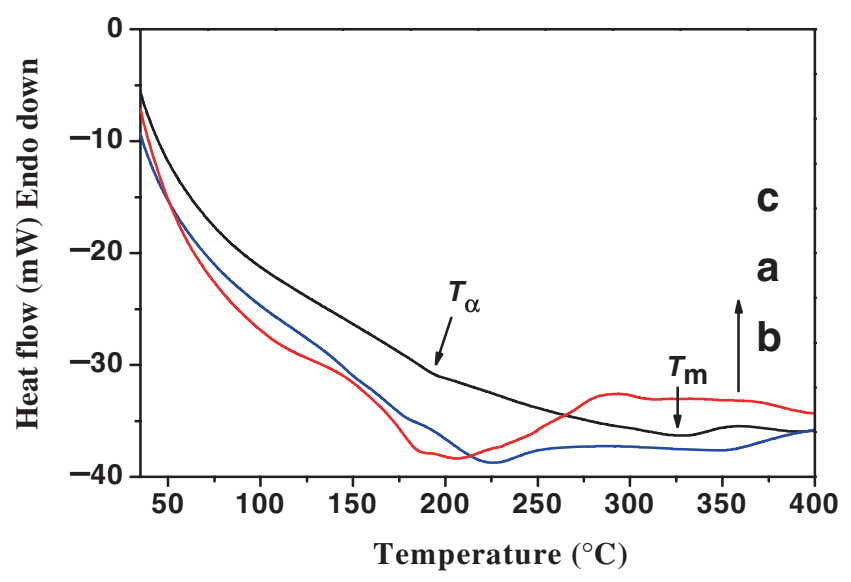

Figure 4. DSC of (a) PVA, (b) PVA-SA and (c) PVA-SA-Rif. 


\subsection{TGA profile}

The thermal stability of PVA under air atmosphere before and after structural modification is given in figure 5. The TGA thermogram of pristine PVA (figure 5a) exhibits a four-step degradation reaction. The first minor weight loss below $100^{\circ} \mathrm{C}$ was associated with the removal of moisture and physisorbed water molecules [28]. The DSC ( $T_{\mathrm{g}}$-below $100^{\circ} \mathrm{C}$ ) and FTIR (-OH stretching around $3500 \mathrm{~cm}^{-1}$ ) results also reflected the same. The second major weight loss around $290^{\circ} \mathrm{C}$ was due to the PVA backbone degradation. During the PVA backbone degradation both inter- and intra-molecular hydrogen bonds were broken and the PVA chains were easily degraded under air atmosphere. The third minor weight loss at $434^{\circ} \mathrm{C}$ was responsible for the breaking of acetate moieties from PVA backbone. The fourth minor weight loss at $535^{\circ} \mathrm{C}$ was due to the breaking of acetate moieties with the removal of $\mathrm{CO}_{2}$ gas. Figure $5 \mathrm{~b}$ represents TGA thermogram of the SA-modified PVA. Four-step degradation processes was noticed. The important point noted here is that the degradation occurs at somewhat lower temperature. This

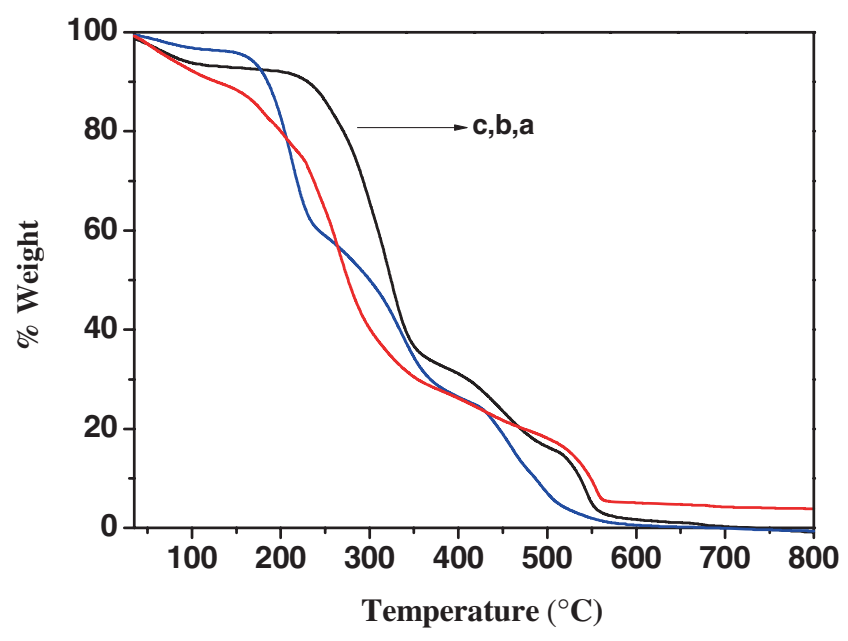

Figure 5. TGA of (a) PVA, (b) PVA-SA and (c) PVA-SA-Rif. is due to the chain scission reaction during the dissolution of PVA at $85^{\circ} \mathrm{C}$ by the oxidative degradation process. As a result, the second major weight loss step occurred around $206^{\circ} \mathrm{C}$. The third major weight loss is corresponding to the cleavage of anhydride units from PVA main chain with the removal of $\mathrm{CO}_{2}$. The appearance of third major weight loss confirmed the structural modification of PVA by SA. The fourth major weight loss at $472^{\circ} \mathrm{C}$ is due to the breaking of acetate moieties from PVA backbone with the simultaneous removal of $\mathrm{CO}_{2}$. Figure $5 \mathrm{c}$ indicates the TGA thermogram of Rif.-grafted SA-modified PVA. The present system yielded a four-step degradation reaction. The first minor weight loss below $150^{\circ} \mathrm{C}$ is due to the removal of moisture, physisorbed, and chemisorbed water molecules [28]. The second minor weight loss around $190^{\circ} \mathrm{C}$ is due to the breaking of linkage between the Rif. and SA. The third major weight loss was associated with the PVA backbone degradation. The fourth one is associated with the degradation of acetate moieties present in the PVA backbone. Above all, the present system exhibits $4.5 \%$ weight residue which remains above $750^{\circ} \mathrm{C}$. In all these three cases the first minor weight loss due to the physisorbed or chemisorbed water molecules were explained earlier in the FTIR spectrum. Hence, the TGA results supported the FTIR peak around $3450 \mathrm{~cm}^{-1}$.

\subsection{SEM analysis}

Figure 6 indicates the SEM images of PVA before and after the structural modification with Rif. Figure 6a denotes the SEM image of pristine PVA. One can see a broken stone-like morphology with some microvoids. Voids are very much useful for the loading of drug [29]. Hence, PVA is an important bio-medical polymer. Figure $6 \mathrm{~b}$ indicates the surface morphology of PVA after the structural modification with Rif. Here, the surface morphology is entirely different from the previous one. The surface looks like a wave. The microvoids disappeared. The change in surface morphology confirmed the chemical grafting of Rif. on the SA-modified PVA backbone.
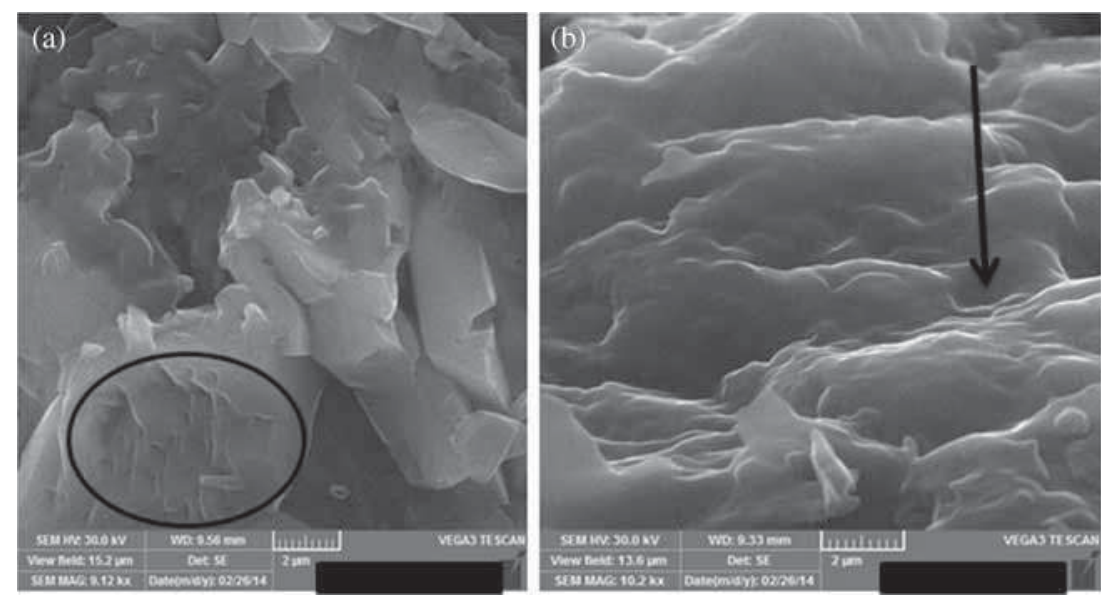

Figure 6. SEM of (a) pristine PVA and (b) Rif.-grafted PVA. 


\subsection{Drug release study}

It is known that Rif. is a drug used to cure tuberculosis. In the present investigation, Rif. is chemically conjugated with the structural-modified PVA. Hence, it is necessary to analyse the drug-release kinetics. Table 1 shows the drug-release data of PVA at $\mathrm{pH}=4.0$ with various drug-release models. The UV-visible spectrum of Rif. recorded at different intervals of time is shown in figure $7 \mathrm{a}-\mathrm{h}$. In order to find out the drugrelease model, zero-order model, first-order model, Higuchi model, Korsemeyer-Peppas and Hixson models were studied [30,31]. The maximum $r^{2}$ value for the Peppas model $(0.97)$ explained the drug-release model. The slope value $(n)$ for the maximum $r^{2}$ was determined as 0.30 (i.e.) $0.30<n$ $=0.89$. This explained the non-Fickian drug transport mechanism. For the sake of comparison, the drug release kinetics was followed at two different $\mathrm{pH}$ values namely 7.3 and 4.0. The drug release kinetics at $\mathrm{pH} 7.3$ was thoroughly studied and the UV-visible spectrum is given in figure $8 \mathrm{a}-1$. The similar study was made for the $\mathrm{pH}$ of 4.0. Under the gastric $\mathrm{pH}$, the drug release followed the first-order release mechanism. This clearly explains the dissolution of water soluble drug in porous matrices. In comparison, the drug-release mechanism at $\mathrm{pH}$ of 7.3 followed the Peppas model with nonFickian drug transportation mechanism. Table 1 explains the drug-release data for two different $\mathrm{pH}$ values.

Table 1. Drug delivery data.

\begin{tabular}{llllllll}
\hline & \multicolumn{3}{c}{$\mathrm{pH}=4.0$} & & \multicolumn{3}{c}{$\mathrm{pH}=7.3$} \\
\cline { 2 - 4 } \cline { 7 - 8 } Model & $R^{2}$ & Slope & Intercept & & $R^{2}$ & Slope & Intercept \\
\hline Zero order & 0.715 & 0.2300 & 11.9 & & 0.68 & 0.0069 & 1.65 \\
First order & 0.799 & 0.0013 & 1.94 & & 0.68 & 3.0900 & 1.99 \\
Higuchi & 0.570 & 0.0756 & 0.81 & & 0.66 & 0.0380 & 0.98 \\
Peppas & 0.690 & 0.6700 & 0.22 & & 0.97 & 0.3040 & 0.85 \\
Hixson & 0.760 & 0.0043 & 4.45 & & 0.68 & 1.090 & 4.61 \\
\hline
\end{tabular}

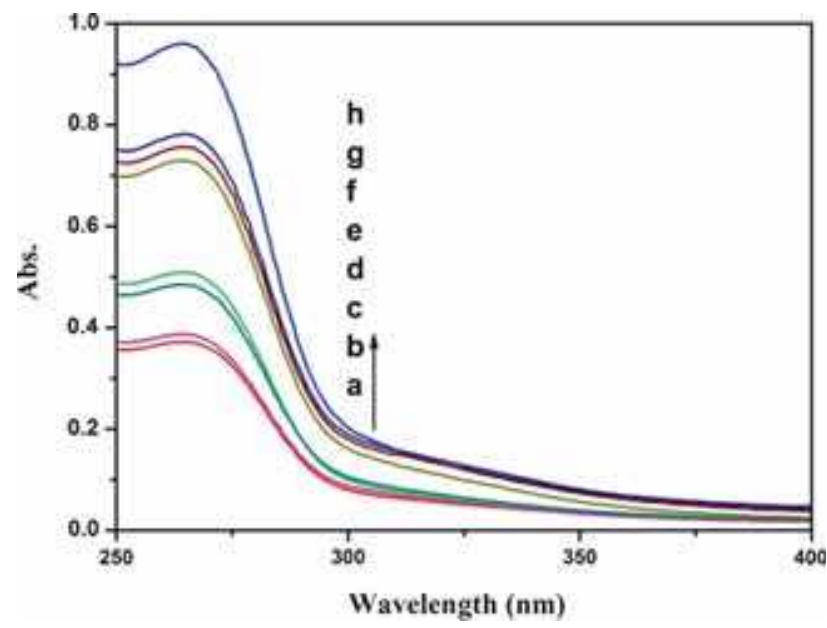

Figure 7. UV-visible spectrum of Rif. released at different intervals of time $(\mathbf{a}-\mathbf{h})$ at a $\mathrm{pH}=4.0$.

\subsection{Mechanical properties}

Table 2 shows the mechanical properties data for three different polymer systems. The pure PVA (P1) exhibited the tensile strength value of $13.96 \mathrm{~kg} \mathrm{~mm}^{-2}$. The SA-modified PVA exhibited the tensile strength value of $1.92 \mathrm{~kg} \mathrm{~mm}^{-2}$. The sudden decrease in tensile strength value of SA-modified PVA (P2) can be explained on the basis of hydrophilicity [28]. PVA on treatment with SA in the presence of S.O. produced the carbonyl functionalized PVA. This leads to the high moisture absorption and the decrease in tensile strength. The Rif.-conjugated structurally modified PVA (P3) exhibited the tensile strength value of $2.25 \mathrm{~kg} \mathrm{~mm}^{-2}$. The tensile strength value of P3 was determined as 2.25 which is lower than that of P1 and greater than that of P2. After the chemical conjugation with Rif. the tensile strength value is little bit increase due to the presence of polynuclear aromatic ring system which is chemically bonded with the PVA backbone. Owing to the presence of aromatic polynuclear phenyl ring the hydrophilic character is reduced. The percentage elongation for P1, P2 and P3 were determined as 122.2, 79.4 and $233.4 \%$. The decrease in percentage elongation for $\mathrm{P} 2$ is due to the carbonyl group functionalized and water seeking SAmodified PVA. The P3 exhibited the highest percentage of elongation due to the presence of phenyl ring in the Rif. The phenyl ring leads to the increase in rigidity of the structure. As a result of increase in percentage elongation one can come to a conclusion that the Rif. is chemically attached with the

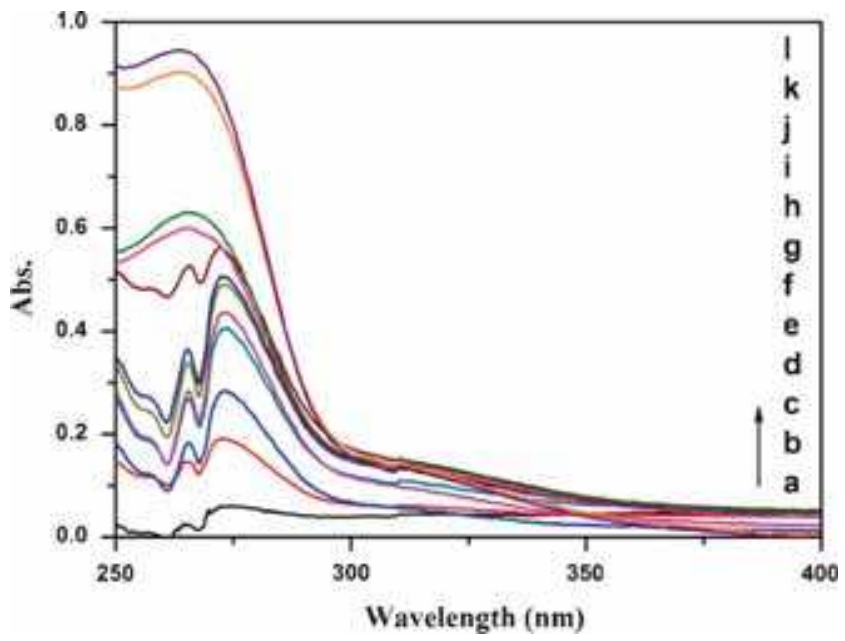

Figure 8. UV-visible spectrum of Rif. released at different intervals of time $(\mathbf{a}-\mathbf{h})$ at a $\mathrm{pH}=7.3$.

Table 2. Mechanical properties of PVA before and after the structural modification.

\begin{tabular}{lccc}
\hline System & $\begin{array}{c}\text { Tensile strength } \\
\left(\mathrm{kg} \mathrm{mm}^{-2}\right)\end{array}$ & $\begin{array}{c}\text { Percentage } \\
\text { elongation (\%) }\end{array}$ & $\begin{array}{c}\text { Ultimate } \\
\text { modulus (MPa) }\end{array}$ \\
\hline PVA (P1) & 13.96 & 122.2 & 360.07 \\
PVA-SA (P2) & 01.91 & 79.4 & 47.96 \\
PVA-SA-Rif. (P3) & 02.52 & 233.4 & 67.48 \\
\hline
\end{tabular}


structurally modified PVA. The ultimate modulus value of pure PVA is greater than that of $\mathrm{P} 2$ and $\mathrm{P} 3$. This is due to the hydrophilic nature of PVA after the structural modification process.

\section{Conclusions}

From the above study the following important points are presented here as conclusions. The increase in $-\mathrm{OH}$ peak area around $3500 \mathrm{~cm}^{-1}$ in the FTIR spectrum confirmed the grafting of Rif. on to SA-modified PVA. The appearance of aromatic protons from 7 to $9 \mathrm{ppm}$ in ${ }^{1} \mathrm{H}$ NMR spectrum and appearance of aromatic carbon signals from 120 to $150 \mathrm{ppm}$ in the ${ }^{13} \mathrm{C}$ NMR spectrum confirmed the structural modification of PVA with Rif. The blue shift in the UV-visible spectrum also confirmed the structural modification of PVA by Rif. The increase in $T_{\mathrm{g}}$ and decrease in $T_{\mathrm{m}}$ from DSC analysis confirmed the chemical grafting of Rif. on to SAmodified PVA. The second and third major weight loss below $350^{\circ} \mathrm{C}$ in the TGA thermogram confirmed the chemical grafting of Rif. on to SA-modified PVA. After the chemical grafting reaction the microvoids present on the PVA disappeared and the same was confirmed by SEM analysis. After the structural modifications, the tensile strength was found to be reduced due to the breaking of inter- and intra-molecular hydrogen bonding in PVA. The \% elongation was increased by two times and behaved like a rubbery material due to the conjugation of phenyl ring with PVA backbone. The drug release activity of Rif.-modified PVA was carried out under two different $\mathrm{pH}$ values. At $\mathrm{pH}=4$ the first-order drug release model was noticed whereas under neutral $\mathrm{pH}$ the system exhibits the Peppas model drug release with non-Fickian drug transportation mechanism. By way of structural modification of PVA by Rif. the aim of the present investigation was achieved.

\section{Acknowledgement}

Mrs G Vijayalakshmi, Assistant Professor, Department of English, is gratefully acknowledged for her valuable help during this manuscript preparation.

\section{References}

[1] Rasida U K, Nayak A K, Binhani B K and Nayak P C $2011 \mathrm{~J}$. Biomater. Nanobiotechnol. 2414

[2] Zu Y, Zasasg Y, Shan C, Zu S, Ge Y, Aevn D and Brid J 2012 Macromolecules $\mathbf{2 5 0} 82$

[3] Mohamad A A and Asok K A 2006 Ionics 1257
[4] Paradosi G, Caralieri F and Chieshi E 2003 J. Mater. Sci. Mater. Med. 14687

[5] Gupta S, Webster J J and Sinha A 2011 J. Mater. Sci. Mater. Med. 221763

[6] Crispim E G, Piai J F, Fajardo A R and Muniz F C 2012 Express Polym. Lett. 6383

[7] Mohammad H N T, Davaran S and Entezami A A 1996 Iran. Polym. J. 3183

[8] Schmedlen R H, Masters K S and West J L 2002 Biomaterials 234325

[9] Vicosa A L, Gomes A C O, Soares B G and Paranhos C M 2009 Express Polym. Lett. 3518

[10] Gao S F, Chem H G, Warg Z H, Cui Z J and Zhang Y H 2012 Plast. Polym. Compos. $\mathbf{4 1} 13$

[11] Lejardi A, Exeberria A, Meautics E and Sarasua J R 2012 Polymer $\mathbf{5 3} 50$

[12] Guerrouani N, Mas A and Schue F 2009 J. Appl. Polym. Sci. 1131188

[13] Farog R F and Mohamed R R 2013 Molecules 18190

[14] Maji P, Gandhi A, Jara S and Maji N 2013 J. Pharm. Sci. Technol. 262

[15] Westedt U, Kalinowski M, Wittman M and Kinsel T $2007 \mathrm{~J}$. Control. Rel. 11941

[16] Ruiz J, Mantecon A and Codiz V 2001 Polymer 426347

[17] Gupta A P and Asora G 2012 Der. Chem. Sin. 31191

[18] Rhim J W, Yeom C K and Kim S W 1998 J. Appl. Polym. Sci. 681717

[19] Muhammed A, Hashash E and Harsanian E 2012 Hydrol. Curr. Res. 31

[20] Zhou Z M, David D J, Mackright W J and Karasz F E 1997 Turk. J. Chem. 2133

[21] Aboutaleb E, Noori M, Gandomi N, Atyabi F, Fazeli M R, Jamalifar H and Dinarvand R 2012 Int. Nano Lett. 233

[22] Asif M 2013 World J. Org. Chem. 114

[23] Bhowmik D, Chiranjib Chandira R M, Jayakar B and Sampath Kumar K P 2009 J. Chem. Pharm. Res. 1113

[24] Gandhi S, Gopinathan Nair R and Anbarasan R 2012 Int. J. Nano Sci. 111

[25] Fathima Parveen M, Umapathi S and Anbarasan R 2009 Nano 4147

[26] Fathima Parveen M, Umapathy S, Dhanalakshmi V and Anbarasan R 2009 J. Mater. Sci. 445852

[27] Gandhi S, Harihara Subramani R, Sivabalan A, Dhanalakshmi V and Anbarasan R 2010 J. Mater. Sci. 451688

[28] Anbarasan R, Pandiarajaguru R, Dhanalakshmi V and Jeyalakshmi T 2010 J. Appl. Polym. Sci. 1172059

[29] Gandhi S, Abiramipriya P, Pooja N, Dhanalakshmi V and Anbarasan R 2011 J. Non-Cryst. Solids 357181

[30] Dash S, Murthy P N, Nath L and Chowdhury P 2010 Acta Pol. Pharm. Drug Res. 67217

[31] Konda N, Arvind G, Shah S and Prashanth P 2013 Int. J. Pharm. Pharm. Sci. 5541 